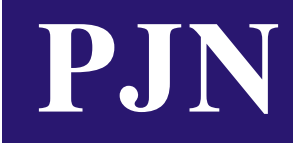

ISSN 1680-5194

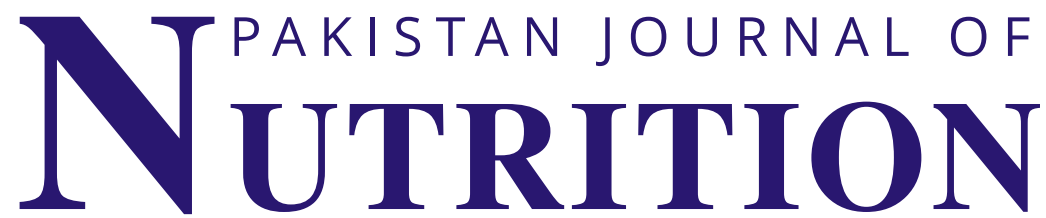

ANSI迫e佔

308 Lasani Town, Sargodha Road, Faisalabad - Pakistan Mob: +92 3003008585 , Fax: +92 418815544

E-mail: editorpjn@gmail.com 


\title{
Nutritional Status of the Temiar Orang Asli Community in Kuala Betis, Gua Musang, Kelantan
}

\author{
1,3,4 Mohd Adzim Khalili Rohin, ${ }^{2}$ Azizul Fadzli Wan Jusoh @Ab Rahim, ${ }^{1}$ Mohd Nizam Zahary, ${ }^{2}$ Aniza Abd Aziz, \\ ${ }^{2}$ Nik Ahmad Shaiffudin Nik Him, ${ }^{2}$ Rosliza Yahaya, ${ }^{1}$ Norhaslinda Ridzwan, ${ }^{1}$ Mimie Noratiqah Jumli and \\ ${ }^{1}$ Sakinah Harun
}

${ }^{1}$ Faculty of Health Sciences, Universiti Sultan Zainal Abidin, Gong Badak Campus, Hafsah Block, 21300 Kuala Nerus, Terengganu Darul Iman, Malaysia

${ }^{2}$ Faculty of Medicine, Universiti Sultan Zainal Abidin, Medical Campus, Jalan Sultan Mahmud, 20400 Kuala Terengganu, Terengganu Darul Iman, Malaysia

${ }^{3}$ Institute for Community (Health) Development, Universiti Sultan Zainal Abidin, Gong Badak Campus, 21300 Kuala Nerus, Terengganu Darul Iman, Malaysia ${ }^{4}$ Centre for Continuing Education (CCE), Universiti Sultan Zainal Abidin, Gong Badak Campus, 21300 Kuala Nerus, Terengganu Darul Iman, Malaysia

\section{Abstract}

Background and Objective: The Temiar are one of the most flexible sub-tribes of Orang Asli in Malaysia and readily adapting to government policies and an urban lifestyle within the villages and cities to which they have been relocated. Such changes can also cause nutritional alterations which affect health. The present study assessed the nutritional status of the relocated Temiar Orang Asli community in Gua Musang, Kelantan, Malaysia. Methodology: A group of 58 adults was screened to participate in this study. The anthropometric assessments included height, weight, body mass index $\left(\mathrm{kg} \mathrm{m}^{-2}\right)$, body fat analysis (\%), Mid Upper Arm Circumference (cm) (MUAC) and Waist Circumference (cm) (WC) were determined. Dietary intake was estimated using data from surveys of self-reported 24-h diet recall across 3 days and data were analyzed using Nutri Pro software and SPSS version 20.0. Results: The mean age of the respondents was $36.69 \pm 1.28$ years. Overall, $9 \%$ of the respondents were underweight, $40 \%$ fell within the normal range, $28 \%$ were overweight and $23 \%$ were obese. The majority of the respondents (84\%) had a normal WC, 16\% were at risk of comorbidities and increased abdominal fat. Based on MUAC, $98 \%$ of the respondents had normal nutrition. However, $41 \%$ had very high, $28 \%$ had high, $29 \%$ had normal and $2 \%$ had low body fat analysis (BFA) levels. The mean of energy (kcal) of the respondents was 1219.10 \pm 423.93 , the mean carbohydrate ( $\mathrm{g}$ ) level was $186.42 \pm 137.73$, the mean protein $(\mathrm{g})$ level was $50.64 \pm 2.12$ and the mean fat $(\mathrm{g}$ ) level was $40.55 \pm 1.89$. Conclusion: The incidence of overweight/obese individuals prominently increased in both men and women according to body mass indices and body fat percentages compared to a previous study.

Key words: Nutrition status, Temiar Orang Asli, anthropometry, $24 \mathrm{~h}$ diet recall, overweight, obesity, body fat analysis

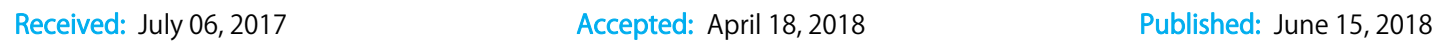

Citation: Mohd Adzim Khalili Rohin, Azizul Fadzli Wan Jusoh@Ab Rahim, Mohd Nizam Zahary, Aniza Abd Aziz, Nik Ahmad Shaiffudin Nik Him, Rosliza Yahaya, Norhaslinda Ridzwan, Mimie Noratiqah Jumli and Sakinah Harun, 2018. Nutritional status of the Temiar Orang Asli community in Kuala Betis, Gua Musang, Kelantan. Pak. J. Nutr., 17: 311-318.

Corresponding Author: Mohd Adzim Khalili Rohin, Faculty of Health Sciences, Universiti Sultan Zainal Abidin, Gong Badak Campus, Hafsah Block, 21300 Kuala Nerus, Terengganu Darul Iman, Malaysia Tel: +6096688522 Fax: +609 6275771

Copyright: () 2018 Mohd Adzim Khalili Rohin et al. This is an open access article distributed under the terms of the creative commons attribution License, which permits unrestricted use, distribution and reproduction in any medium, provided the original author and source are credited.

Competing Interest: The authors have declared that no competing interest exists.

Data Availability: All relevant data are within the paper and its supporting information files. 


\section{INTRODUCTION}

Orang Asli have been an indigenous people from Peninsular Malaysia for about 5000-25,000 years and are currently in the minority $(0.6 \%)^{1}$. Orang Asli populations include large tribes and smaller sub-tribes, some of which are virtually extinct. The three largest tribes include the Proto Malay (subtribes: Orang Seletar and Jakun), Senoi (subtribes: Temiar, Mahmeri and Semai) and Negrito (subtribes: Jehai, Mendriq and Batek) $)^{2}$. Orang Asli are highly diverse in genetic, socioeconomic and geographical background as the majority still reside in distant, rural areas of Malaysia ${ }^{3}$.

Over the years, many Orang Asli have undergone government-sanctioned relocations to more developed and urban areas in the region'. They are given proper facilities, homes with basic features, healthcare services and access to various programs to ensure improvement in their quality of life ${ }^{4}$. However, adapting to an urbanized lifestyle often leads to unhealthy dietary habits, resulting in increasing prevalence of chronic diseases, such as hypertension and diabetes ${ }^{2}$.

Currently, the Temiar are one of the most flexible sub-tribes of Orang Asli, readily adapting to government policies and an urban lifestyle within the villages and cities to which they have been relocated ${ }^{\prime}$. As a result, this population may have experienced significant nutritional alterations ${ }^{4}$. Previously, Yusof et al..$^{5}$ investigated anthropometric indices and lifestyle practices of Jahai and Temiar sub-tribes of Orang Asli in Lembah Belum, Grik, Malaysia. However, according to their study, the majority of subjects were Jahai (59\%), which were less diverse than the Temiar and the location of the study was not in one of the main relocation areas of the Temiar Orang Asli.

Therefore, the nutritional status of Temiar Orang Asli populations at relocation areas is currently unknown. Nutrition is used as an indicator of standard living or status and anthropometric measurements represent an important component of nutritional assessment ${ }^{6}$. Thus, the present study assessed the nutritional status of the Temiar Orang Asli community with regard to anthropometric indices and diet within their relocation areas.

\section{MATERIALS AND METHODS}

Research locations: The present study included the Temiar Orang Asli community in RPS Kuala Betis, Gua Musang, Kelantan, Malaysia. RPS Kuala Betis is situated about $30 \mathrm{~km}$ from Bandar Gua Musang. This site was pragmatically chosen to ensure adequate representation of the Temiar population who underwent urbanization and modern development. Figure 1 shows a map of the location of the study population.

Respondents: This survey included 58 respondents between 18 and 65 years old from the Temiar Orang Asli community. Respondents who were not within this age range or refused to participate were not included, in addition, pregnant and lactating women were excluded from this study. Prior to the interview session, informed consent (initialized consent form) was obtained from each respondent. Ethics approval was obtained from the Research Ethics Committee of Faculty of Medicine, Universiti Sultan Zainal Abidin (UniSZA) with reference number UHREC/2016/3/012.

Socio-demographic background: Upon receiving written consent, respondents were given a survey of sociodemographic data, which consisted of seven questions regarding religion, age, gender, education level, occupation, monthly income and members of the household.

Anthropometric assessments: Anthropometric assessments consisted of measuring weight, height, body mass index (BMI) $\left(\mathrm{kg} \mathrm{m}^{-2}\right)$, body fat analysis (BFA) (\%), Mid Upper Arm Circumference (MUAC) (cm) and Waist Circumference (WC) $(\mathrm{cm})$. Height was measured while respondents were in a standing position without wearing shoes to nearest $0.1 \mathrm{~cm}$, a measuring tape attached to a wall was used and a ruler was applied to the top of the head. Weight (in light clothing) was taken using the Omron HBF-375 Body Composition Monitor (Asian Model, Australia). The BMI and BFA were also taken using the Omron HBF-375 Body Composition Monitor using the criteria of World Health Organization ${ }^{7}$ Lohman $^{8}$ and Nagamine $^{9}$. The WC and MUAC were measured using measuring tape. The WC was measured at the level of the umbilicus while the respondent was in standing position with the abdomen relaxed, arms at the sides and feet together. MUAC was measured while the respondent was in the standing position, with arms relaxed and without sleeves. The midpoint of the left upper arm was determined by measuring the length from the tip of the shoulder to the tip of the elbow, length was divided by two, according to Collins ${ }^{10}$.

Dietary intake: Dietary intake was evaluated using $24 \mathrm{~h}$ diet recall survey data from each respondent across 3 days. This study focused on energy and macronutrients and did not investigate dietary patterns. A trained dietary interviewer collected dietary data with a questionnaire in a face-to-face interview. During the interview, respondents were asked to 


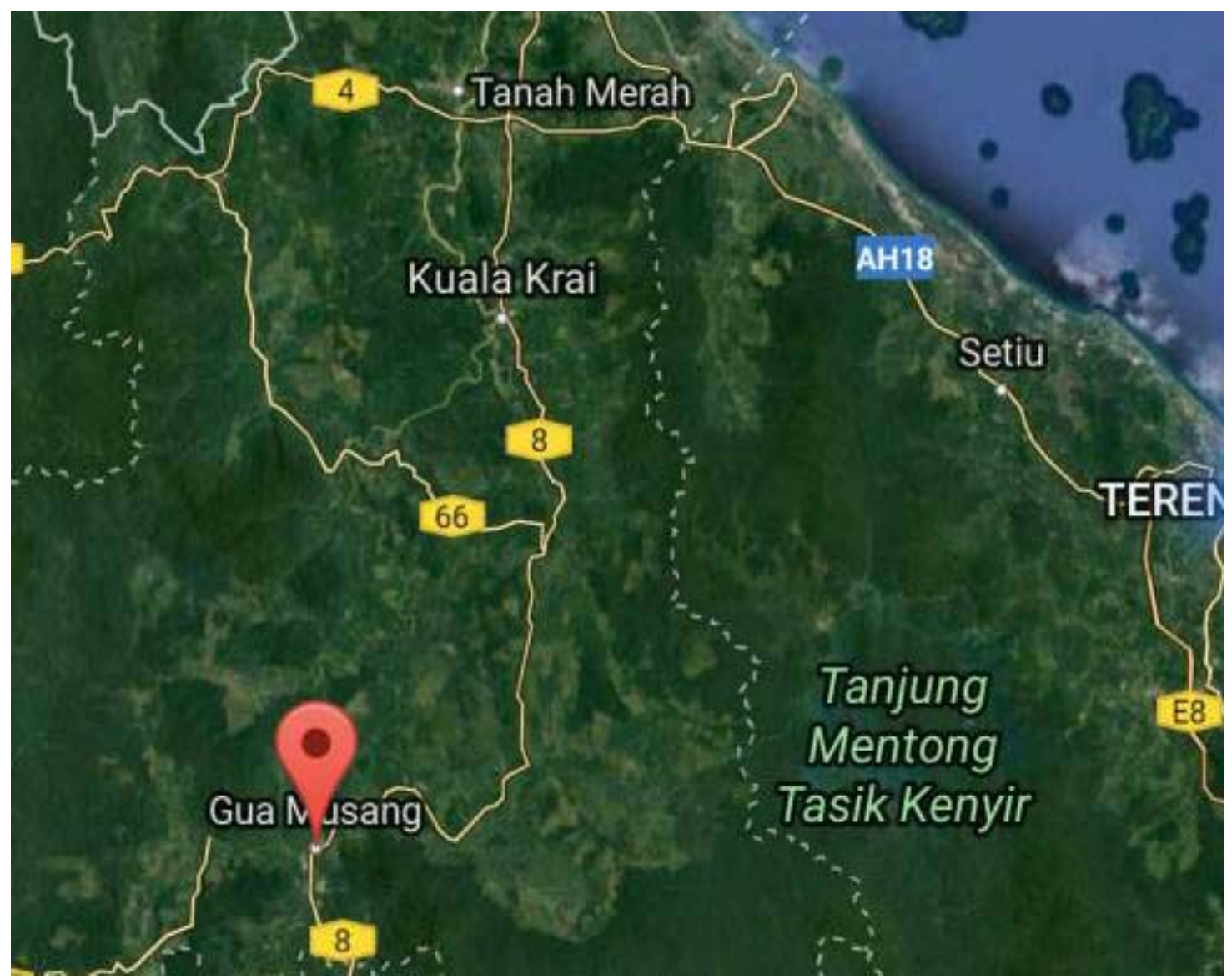

Fig. 1: Location of study population in Orang Asli relocation area, Gua Musang, Kelantan, Malaysia

describe the usual foods and beverages they consumed in two weekdays and one weekend day. Respondents also were asked to clearly and specifically describe every item of food and beverage consumed as well as how the food was prepared and portions consumed. Dietary data obtained in homemade measurements were converted into grams and millilitres to permit chemical analysis of food intake. Foods not found in the software program were added from diverse composition tables and food labels from the Nutrient Composition of Malaysian Foods ${ }^{11}$. The data were analyzed using Nutritionist Pro $^{\mathrm{TM}}$ software (Axxya System, US Nutrition Facts). Diet quality was compared with Recommended Nutrient Intakes for Malaysia $(\mathrm{RNI})^{12}$ and Recommended Dietary Allowances $(\mathrm{RDA})^{13}$.

Statistical analysis: Analysis were performed using the IBM SPSS Statistical Package for the Social Sciences (SPSS), version 20.0 software (IBM Corp. Armonk, NY, US). The data were expressed as means \pm standard deviations (SD). Comparisons between groups were performed using Student's t-tests and categorical variables were compared using chi-square tests. Normal distribution of data was verified with a histogram. A $p$-value of less than 0.05 was considered to be statistically significant.

\section{RESULTS AND DISCUSSION}

Socio-demographic characteristics: Complete data were available for 58 respondents. The age of the respondents ranged from 18-60 years with a mean of $36.69 \pm 1.28$ years. Over $52 \%$ of the respondents had no formal education, 16 and $32 \%$ had received primary school and secondary school education, respectively. Most of the respondents were married $(74 \%), 14 \%$ were unmarried and $12 \%$ were widow/widowers. Household size ranged from 1-15 people. Nearly half of the respondents $(45 \%)$ received a monthly income in the range of RM 0-200. Table 1 shows the socio-demographic characteristics of the respondents. 
Table 1: Demographic and socioeconomic characteristics of the respondents

\begin{tabular}{lr}
\multicolumn{1}{c}{$(\mathrm{n}=58)$} & $\mathrm{N}(\%)$ \\
\hline Characteristics & \\
\hline Gender & $15(26)$ \\
Male & $43(74)$ \\
Female & \\
Religion & $22(38)$ \\
Islam & $1(2)$ \\
Buddha & $35(60)$ \\
Others & \\
Education level & $30(52)$ \\
Un-school & $9(16)$ \\
Primary school & $19(32)$ \\
Secondary school & \\
Marital status & $43(74)$ \\
Married & $8(14)$ \\
Unmarried & $7(12)$ \\
Widow/Widower & \\
Occupation status & $37(64)$ \\
Unemployed & $18(31)$ \\
Rural & $3(5)$ \\
Urban & \\
Household size & $6(10)$ \\
1-3 & $27(47)$ \\
$4-6$ & $8(14)$ \\
$7-9$ & $13(22)$ \\
$10-12$ & $4(7)$ \\
13-15 & \\
Monthly income (RM) & $26(45)$ \\
$0-200$ & $9(15)$ \\
201-400 & $11(19)$ \\
401-600 & $3(5)$ \\
801-800 & $5(9)$ \\
1001 and above & $4(7)$ \\
\hline & \\
&
\end{tabular}

Anthropometric indices and dietary assessment (24 h diet recall): Anthropometry involves external measurement of morphological traits of humans and has an important place in nutritional assessment ${ }^{14}$. These measurements are easily performed with appropriate training and applicable in clinical practice. Body mass index (BMI) is a common metric currently used for defining anthropometric characteristics in adults and categorizing them into groups, while Waist Circumference (WC) provides an estimate of abdominal fat ${ }^{15}$. Therefore, the present study was used BMI and WC to classify body status among respondents.

Table 2 describes the result of anthropometric indices and dietary assessment of respondents. The mean \pm standard deviation (SD) weight of respondents was $59.5 \pm 13.59 \mathrm{~kg}$

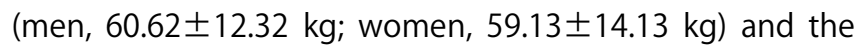
Mean $\pm S D$ height was $154 \pm 8.54 \mathrm{~cm}$ (men, $160 \pm 5.92 \mathrm{~cm}$, women, $151 \pm 7.92 \mathrm{~cm}$ ). Teong ${ }^{16}$ previously reported the body weight of the Orang Asli community was lower than that of the general Malaysian population (men, $55 \mathrm{~kg}$; women, $50 \mathrm{~kg}$ ) however, the mean body weight of both genders was higher than that of the general Malaysian population.
Table 2: Anthropometric indices and dietary assessments (energy and macronutrients) of the respondents $(n=58)$

\begin{tabular}{|c|c|c|}
\hline Anthropometric indices and dietary intake & $\mathrm{N}(\%)$ & Mean $\pm S D$ \\
\hline Weight (kg) & $58(100)$ & $59.50 \pm 13.59$ \\
\hline Height (cm) & $58(100)$ & $1.54 \pm 8.54$ \\
\hline \multicolumn{3}{|l|}{ BMI $\left(\mathbf{k g ~ m}^{-2}\right)$} \\
\hline Underweight & $5(9)$ & $16.30 \pm 1.07$ \\
\hline Normal & $23(40)$ & $21.83 \pm 1.75$ \\
\hline Overweight & $16(28)$ & $27.16 \pm 1.71$ \\
\hline Obese 1 & $12(20)$ & $30.76 \pm 3.40$ \\
\hline Obese 2 & $2(3)$ & $36.70 \pm 2.12$ \\
\hline Obese 3 & 0 & 0 \\
\hline \multicolumn{3}{|l|}{ WC (cm) } \\
\hline At risk & $9(16)$ & $96.51 \pm 7.20$ \\
\hline Normal & $49(84)$ & $73.46 \pm 11.27$ \\
\hline \multicolumn{3}{|l|}{ MUAC (cm) } \\
\hline Normal nutrition & $57(98)$ & $27.69 \pm 4.37$ \\
\hline Moderate under nutrition & 0 & 0 \\
\hline Severe under nutrition & $1(2)$ & 9.00 \\
\hline \multicolumn{3}{|l|}{ BFA (\%) } \\
\hline Very high & $24(41)$ & $37.37 \pm 6.87$ \\
\hline High & $16(28)$ & $28.65 \pm 4.99$ \\
\hline Normal & $17(29)$ & $24.52 \pm 4.65$ \\
\hline Low & $1(2)$ & 9.60 \\
\hline Energy (kcal) & $58(100)$ & $1.22 \pm 422.97$ \\
\hline \multicolumn{3}{|l|}{ Carbohydrate (\% of energy) $(60.72 \pm 32.15)$} \\
\hline$<45$ & $9(16)$ & $40.67 \pm 3.12$ \\
\hline $45-0$ & $33(57)$ & $53.67 \pm 3.49$ \\
\hline$>60$ & $16(27)$ & $86.56 \pm 53.23$ \\
\hline \multicolumn{3}{|l|}{ Protein (\% of energy) (16.58 \pm 4.97$)$} \\
\hline$<15$ & $19(33)$ & $10.89 \pm 2.33$ \\
\hline $15-20$ & $28(48)$ & $17.79 \pm 1.71$ \\
\hline$>20$ & $11(19)$ & $23.36 \pm 2.62$ \\
\hline \multicolumn{3}{|l|}{ Fat (\% of energy) ( $29.60 \pm 8.08)$} \\
\hline$<25$ & $14(24)$ & $19.64 \pm 4.16$ \\
\hline $25-35$ & $35(60)$ & $30.34 \pm 3.29$ \\
\hline$>35$ & $8(16)$ & $41.75 \pm 6.27$ \\
\hline
\end{tabular}

These results are also inconsistent with a study conducted by Yusof et al.5, on Jahai and Temiar subtribes in Lembah Belum Grik, Malaysia who reported lower mean weights compared to the general Malaysian population (men, $52 \mathrm{~kg}$; women, $46 \mathrm{~kg}$ ). In contrast, the present study shows the mean body weights of men and women were 60 and $59 \mathrm{~kg}$, respectively. This represents an increase in body weights of men $(23 \%)$ and women $(28 \%)$ in just a decade. These results are consistent with the knowledge that men generally have a higher mean body weight than women.

The Mean \pm SD BMI of overweight respondents was $25.19 \pm 5.30 \mathrm{~kg} \mathrm{~m}^{-2}$ with no significant difference between men and women. Using World Health Organization (WHO $)^{7}$ classifications, $9 \%$ of respondents were classified as underweight, $40 \%$ were normal weight and $51 \%$ were overweight/obese. Body fat percentages indicated that $2 \%$ of respondents had low body fat assessment (BFA) levels, 29\% had normal and $69 \%$ had a high/very high BFA. Overall, these results show that most respondents were considered overweight/obese. 
While BMI is not a direct measure of body fat, it does measure body mass, which includes both fat and lean tissue. Both low levels of lean tissue mass and high levels of body fat are independently associated with an increased risk of mortality ${ }^{14}$. However, the present study showed that a high $\mathrm{BMI}$ and body fat percentage were associated with being overweight/obese, all of which greatly increase the risk of comorbidities. A study conducted by Yusof et al. ${ }^{5}$ reported that $68.2 \%$ body fat was associated with an increase in overweight/obesity, while $51.4 \%$ body fat was related to a decrease in underweight individuals among Orang Asli populations.

According to the National Institutes of Health ${ }^{17}$ criteria for WC (men, $\geq 102 \mathrm{~cm}$; women, $\geq 88 \mathrm{~cm}$ ), $16 \%$ of respondents exhibited central obesity. The present study showed that WC percentages were $15.2 \%$ higher than those reported by Yusof et al. ${ }^{5}$ Excess abdominal fat is an important risk factor for disease and can also be a marker for increased health risks even in persons of normal weight ${ }^{17}$. In addition, the majority of respondents in the present study were categorized as having normal nutrition $(27.69 \pm 4.37 \mathrm{~cm})$ based on criteria set by Collins ${ }^{10}$, where a Mid-Upper Arm Circumference (MUAC) less than $16.0 \mathrm{~cm}$ is considered as severe malnutrition. MUAC is useful for indicating acute adult malnutrition and estimating prevalence of malnutrition at a population level ${ }^{10}$.

Based on self-reported 24-h diet recall data, the Mean $\pm S D$ energy intake of men and women was $1461.41 \pm 536.41$ and $1134.67 \pm 344.41 \mathrm{kcal}$, respectively. Compared to the Reference Nutrition Intake levels ${ }^{12}$, men and women consumed 59-73\% (2010-2460 kcal) and 52-64\% (1780-2180 kcal) of recommended energy levels. The mean \pm SD protein consumption in the present study was $57.40 \pm 24.46 \mathrm{~g}$ for men and $48.27 \pm 19.74 \mathrm{~g}$ for women, both of which were lower than Reference Nutrition Intake recommendations (men, 59-62 g, women, 51-55 g). These data are supported by that of Haemamalar et al. ${ }^{18}$, who reported that Orang Asli people rarely consumed chicken or beef sold in the market due to their high prices.

Herein, the Mean $\pm S D$ fat consumption was $49.80 \pm 22.38 \mathrm{~g}$ for men and $37.32 \pm 16.64 \mathrm{~g}$ for women, which equates to $29.60 \%$ protein intake overall based on Malaysian Dietary Guidelines (25-35\%) ${ }^{19}$. The Temiar Orang Asli community depends more on carbohydrate-rich food sources, such as tapioca, yam, sweet potato and wheat flour, which explains why the mean carbohydrate intake percentage (60.72 $232.15 \%)$ was slightly exceeded normal Malaysian Dietary Guideline values (46-60\%) in the current study ${ }^{19}$. The present data on the Temiar Orang Asli are consistent with that of the Che Wong people which were shown to have very poor dietary diversity due to lack of food availability ${ }^{18}$.

\section{Association between monthly income and anthropometric} indices: In the present study, no significant association was found between monthly income (RM) and any of the anthropometric indices (BMI, MUAC, WC and BFA). Previously, Haemamalar et al. ${ }^{18}$ reported a significant association between household income and waist circumference in a community of Che Wong women. These data were supported by that of Chen and Tunstall-Pedoe ${ }^{20}$, who also found that monthly income (RM) was significantly related to women's waist circumference because when women have their own income, they have perceived equal economic distribution as men. Therefore, they are more likely favoured in terms of food allocation which could enhance their nutritional status ${ }^{21}$. Table 3 shows that no significant association was found between monthly income (RM) and anthropometric indices based on gender.

\section{Comparison of anthropometric indices and dietary assessments across the gender: Table 4 shows} anthropometric indices and dietary assessments according to gender. The Mean \pm SD BMI was $23.51 \pm 4.77 \mathrm{~kg} \mathrm{~m}^{-2}$ for men and $25.77 \pm 5.41 \mathrm{~kg} \mathrm{~m}^{-2}$ for women and no significant difference was found between them. There were also no differences between WC, MUAC, carbohydrates and protein levels between men and women. However, there was a significant difference between male and female BFA, energy and fat levels (all $p<0.05$ ) as the mean value of BFA of women was very high.

In Siberian Orang Asli, the prevalence of obesity in women $(12 \%)$ is reportedly higher than men $(7 \%)^{21}$. This was also reported by Haemamalar et $a / .^{18}$, who showed the prevalence of overweight Che Wong Orang Asli women was higher (28.6\%) than men (10.8\%). Likewise, the present study found that Temiar Orang Asli women had a higher prevalence of overweight/obesity (54\%) compared to men (47\%). These findings are also consistent with the idea that women accumulate fat subcutaneously whereas men do not ${ }^{22-23}$.

Based on self-reported 24-h diet recall surveys over 3 day, $90 \%$ of Temiar Orang Asli respondents tended to consume sweetened condensed milk, which added to hot beverages. On average, the Temiar Orang Asli tended to consume sweetened condensed milk three to four times a day. In addition, the fact that most men worked away from 
Pak. J. Nutr., 17 (7): 311-318, 2018

Table 3: Association between monthly income (RM) and BMI, WC, MUAC and BFA

\begin{tabular}{lcccc}
\hline Variables & BMI ( $p$-value) & WC (p-value) & MUAC (p-value) \\
\hline Monthly income (RM) & 0.77 & 0.60 & BFA (p-value) & 0.16 \\
\hline
\end{tabular}

Pearson chi-square, ${ }^{*} \mathrm{p}<0.05$

Table 4: Comparison of mean between anthropometric indices (BMI, WC, MUAC, BFA), dietary assessments and gender

\begin{tabular}{|c|c|c|c|}
\hline \multirow[b]{2}{*}{ Characteristics } & \multicolumn{2}{|c|}{ Gender (Mean士SD) } & \multirow[b]{2}{*}{ p-value } \\
\hline & Male $(n=15)$ & Female $(n=43)$ & \\
\hline Weight (kg) & $60.62 \pm 12.32$ & $59.13 \pm 14.13$ & 0.37 \\
\hline Height (cm) & $160.00 \pm 5.92$ & $151.00 \pm 7.92$ & 0.54 \\
\hline $\mathrm{BMI}\left(\mathrm{kg} \mathrm{m}^{-2}\right)$ & $23.51 \pm 4.77$ & $25.77 \pm 5.41$ & 0.16 \\
\hline$W C(\mathrm{~cm})$ & $79.21 \pm 11.57$ & $76.27 \pm 14.29$ & 0.48 \\
\hline $\operatorname{MUAC}(\mathrm{cm})$ & $25.79 \pm 6.27$ & $27.93 \pm 4.40$ & 0.15 \\
\hline BFA (\%) & $22.58 \pm 6.42$ & $34.56 \pm 7.10$ & $0.00^{*}$ \\
\hline Energy (kcal) & $1461.41 \pm 536.41$ & $1134.67 \pm 344.41$ & $0.01 *$ \\
\hline Carbohydrates (g) & $230.47 \pm 2.56$ & $75.59 \pm 1.62$ & 0.14 \\
\hline Protein (g) & $57.40 \pm 24.46$ & $48.27 \pm 19.74$ & 0.15 \\
\hline Fat (g) & $49.80 \pm 22.38$ & $37.32 \pm 16.64$ & $0.03^{*}$ \\
\hline
\end{tabular}

Independent t-test, ${ }^{*} \mathrm{p}<0.05$

Table 5: Correlation between energy, macronutrients consumptions and BMI, WC, MUAC and BFA

\begin{tabular}{|c|c|c|c|c|c|c|c|c|}
\hline \multirow[b]{2}{*}{ Variables } & \multicolumn{2}{|l|}{ BMI } & \multicolumn{2}{|c|}{ MUAC } & \multicolumn{2}{|l|}{ WC } & \multicolumn{2}{|l|}{ BFA } \\
\hline & $r$ & $p$-value & r & $p$-value & r & p-value & r & $p$-value \\
\hline Energy (kcal) & -0.05 & 0.70 & -0.04 & 0.78 & 0.01 & 0.94 & -0.24 & 0.07 \\
\hline Carbohydrate (g) & 0.13 & 0.32 & 0.13 & 0.35 & -0.23 & 0.09 & -0.08 & 0.54 \\
\hline Protein (g) & -0.12 & 0.37 & -0.17 & 0.20 & -0.06 & 0.68 & -0.15 & 0.25 \\
\hline Fat (g) & $(0.10$ & 0.45 & -0.09 & 0.52 & 0.04 & 0.78 & 0.26 & $0.05^{*}$ \\
\hline
\end{tabular}

Pearson correlation, ${ }^{*} \mathrm{p}<0.05$

home every day while the women lived at home and this may have contributed to the higher prevalence of obesity in Temiar women than men.

\section{Correlation between dietary assessments and} anthropometric indices: The correlation between dietary assessments (energy and macronutrients) and anthropometric indices (BMI, WC, MUAC and BFA) of the respondents are shown in Table 5 . There was a significant correlation between fat and BFA levels $(r=0.26, p<0.05)$. The percentage of energy from fat in the diet is thought to be an important determinant of body fat. Comparison of diets and prevalence of overweight/obesity between affluent and poor countries have been used to support this relationship ${ }^{24}$.

Although numerous studies have reported a high prevalence of malnutrition in Orang Asli people ${ }^{2,25-26}$, the findings of the current as well as a previous study ${ }^{18}$ support that overweight/obesity is a rising nutritional concern among the Orang Asli community in Malaysia. Moreover, comparison of current results with previous data ${ }^{5}$ showed the incidence of overweight/obesity in Temiar Orang Asli populations rose sharply within years after being relocated. Globally, the Orang Asli community is being impacted by a rapid socioeconomic transition that has led to increased prevalence of diet-linked chronic diseases, such as obesity and cardiovascular diseases ${ }^{27}$.

\section{CONCLUSION}

The relationship between anthropometric indices, dietary assessments and sociodemographic factors is well-understood when assessing nutritional status of different populations. Current results revealed overweight/obesity to be higher in both men and women with high BMls and body fat percentages. Furthermore, significant differences in energy, BFA and fat levels were found between Temiar men and women. As indicated by the current results, relocated Temiar Orang Asli communities are at higher risk for developing communicable and diet-linked chronic diseases due to an urbanized lifestyle and associated alterations in nutrition.

\section{SIGNIFICANCE STATEMENT}

This study evaluated emerging cases of overweight and obesity in BMI and BFA levels of the Temiar Orang Asli community in Malaysia and found that this community may 
be experiencing a nutrition transition. The results of this study may help researchers to understand more about the nutrition, biochemistry and genetics of the Temiar Orang Asli community. According to researchers knowledge, the current study evaluate the nutritional status of Temiar Orang Asli community in Malaysia after decade. Therefore, this study presents a new theory of nutrition transition in Temiar Orang Asli community.

\section{ACKNOWLEDGMENTS}

The authors would like to thank the Ministry of High Education for financial aid (KPT/2015/RAGS/RR170), the Universiti Sultan Zainal Abidin (UniSZA) for ethics approval (UHREC/2016/3/012) and the Faculty of Medicines for providing facilities. The authors would also like to thank the Temiar Orang Asli community from Kuala Betis, Gua Musang, Kelantan for their warm welcome and willingness to participate in this study. We extend additional thanks to the collaborative researchers who participated in this research.

\section{REFERENCES}

1. Nordin, R., M.A. Witbrodt and M.S. Hassan, 2016. Paternalistic approach towards the Orang Asli in Malaysia: Tracing its origin and justifications. Geografia-Malaysian J. Soc. Space, 12: 51-59.

2. Lim, H.M. and H.L. Chee, 1998. Nutritional status and reproductive health of Orang Asli women in two villages in Kuantan, Pahang. Malaysian J. Nutr., 4: 31-54.

3. Jinam, T.A., L.C. Hong, M.E. Phipps, M. Stoneking and M. Ameen et al., 2012. Evolutionary history of continental Southeast Asians: Early train hypothesis based on genetic analysis of mitochondrial and autosomal DNA data. Mol. Biol. Evolution, 29: 3513-3527.

4. Sharifah Zahhura, S.A., P. Nilan and J. Germov, 2012. Food restrictions during pregnancy among indigenous Temiar women in Peninsular Malaysia. Malaysia J. Nutr., 18: 243-253.

5. Yusof, H.M., T.S. Ching, R. Ibrahim and S. Lola, 2007. Anthropometric indices and life style practices of the indigenous Orang Asli adults in Lembah Belum, grik of peninsular Malaysia. Asia Pac. J. Clin. Nutr., 16: 49-55.

6. Frazao, E., 1998. High Costs of Poor Eating Patterns in the United States. In: America's Eating Habits: Changes and Consequences, Frazao, E. (Ed.).US Department of Agriculture, Washington DC., pp: 5-32.
7. WHO., 1995. Physical Status: The Use and Interpretation of Anthropometry (Technical Report Series No. 854). World Health Organization, Geneva, Switzerland, ISBN-13: 9789241208543, Pages: 452.

8. Lohman, T.G., 1986. Applicability of Body Composition Techniques and Constants for Children and Youths. In: Exercise and Sport Sciences Reviews, Pandolf, K.B. (Ed.)., Macmillan, New York, pp: 325-357.

9. Nagamine, S., 1972. Diagnosis of obesity from subcutaneous fat deposition. J. Jpn. Med. Assoc., 68: 919-924.

10. Collins, S., 1996. Using middle upper arm circumference to assess severe adult malnutrition during famine. J. Am. Med. Assoc., 276: 391-395.

11. Tee, E.S., 1998. Nutrient composition of Malaysian foods: A preliminary table 1998. Division of Human Nutrition, Institute for Medical Research, Kuala Lumpur, pp: 73.

12. Recommended Nutrient Intakes for Malaysia (RNI), 2005. A report of the technical working group on nutritional guidelines. National Coordinating Committee on Food and Nutrition, Ministry of Health Malaysia, Putrajaya.

13. Recommended Dietary Allowances (RDA), 1997. Dietary Reference Intakes (DRIs): Recommended dietary allowances and adequate intakes, elements. Food and Nutrition Board, Institute of Medicine, National Academies.

14. Ulijaszek, S.J. and D.A. Kerr, 1999. Anthropometric measurement error and the assessment of nutritional status. Br. J. Nutr., 82: 165-177.

15. Nuttall, F.Q., 2015. Body mass index. Obesity, BMI and health: A critical review. Nutr. Today, 50: 117-128.

16. Teong, T.S., 1975. Recommended daily dietary intakes for peninsular Malaysia. Med. J. Malaysia, 30: 38-42.

17. National Institute of Health, 1998. Clinical Guidelines on the Identification, Evaluation and Treatment of Overweight and Obesity in Adults. National Institutes of Health, National Heart Lung and Blood Institute, UK.

18. Haemamalar, K., M.S. Zalilah and A.N. Azhanie, 2010. Nutritional status of Orang Asli (Che Wong tribe) adults in krau wildlife reserve, Pahang. Malaysian J. Nutr., 16: 55-68.

19. MDG., 2010. National coordinating committee on food and nutrition. Malaysian Dietary Guidelines, Ministry of Health Malaysia, Malaysia.

20. Chen, R. and H. Tunstall-Pedoe, 2005. Socioeconomic deprivation and waist circumference in men and women: The Scottish MONICA surveys 1989-1995. Eur. J. Epidemiol., 20: 141-147.

21. Luo, W., F. Zhai, S. Jin and K. Ge, 2001. Intrahousehold food distribution: A case study of eight provinces in China. Asia Pac. J. Clin. Nutr., 10: 19-28. 
22. James, W.P., A. Ferro-Luzzi and J.C. Waterlow, 1988. Definition of chronic energy deficiency in adults. Report of a working party of the International Dietary Energy Consultative Group. Eur. J. Clin. Nutr., 42: 969-981.

23. Nube, M., W.K. Asenso-Okyere and G.J.M. van den Boom, 1998. Body mass index as indicator of standard of living in developing countries. Eur. J. Clin. Nutr., 52: 136-144.

24. Willett, W.C. and R.L. Leibel, 2002. Dietary fat is not a major determinant of body fat. Am. J. Med., 113: 47-59.
25. Khor, G.L., 1988. Malnutrition among Semai children. Med. J. Mala., 43: 318-326.

26. Ali, O. and Z.M. Isa, 1995. Nutritional status of women and children in Malaysian rural populations. Asia Pac. J. Clin. Nutr., 4: 319-324.

27. Durie, M.H., 2003. The health of indigenous peoples: Depends on genetics, politics and socioeconomic factors. Br. Med. J., 326: 510-511. 